\title{
PARA ALÉM DA FRASE: OS RECURSOS DE PONTUAÇÃO COMO ELEMENTOS DE NATUREZATEXTUAL E SOCIODISCURSIVA
}

\author{
Marco Antônio de Oliveira* \\ Solange R. Bonomo Assumpção*
}

$\mathrm{O}$ objetivo principal deste texto é o de apresentar alguns dos resultados obtidos em duas pesquisas que se ocuparam da gênese da pontuação em textos de alunos das quatro séries iniciais do Ensino Fundamental ou ciclos correspondentes. Os dados utilizados provêm de dois corpora diferentes: o primeiro, coletado em 1987, é constituído por 160 redações, e o segundo, coletado em 1999, compõe-se de 192 redações.

O quadro teórico que norteia esta análise pode ser situado, essencialmente, nos trabalhos de Beaugrande (1997), Schneuwly (1988) e Bronckart (1999). De Beaugrande adotamos os seguintes pressupostos: a) um texto é um "evento comunicativo, no qual convergem ações lingüísticas, sociais e cognitivas"; b) um texto, enquanto sistema real, revela escolhas estratégicas, discursivamente orientadas, em termos dos elementos lingüísticos dos quais ele se utiliza; c) o processamento do discurso conduz à textualização, e a pontuação se configura como um mecanismo de textualização.

* Universidade Federal de Minas Gerais. 
De Schneuwly adotamos a idéia de que a pontuação está diretamente correlacionada às operações de planejamento discursivo e, portanto, não pode ser vista, em sua gênese, como desvio de uma prescrição gramatical adotada. Resta-nos, pois, saber quais são as funções discursivas que um determinado uso de um recurso de pontuação pode nos revelar. De Bronckart adotamos a perspectiva sociointeracionista, na qual as ações de linguagem são vistas em sua relação com a atividade humana em geral, em seus aspectos históricos e sociais, manifestando-se nos gêneros textuais empíricos. ${ }^{1}$

Por aquilo que se expôs até aqui, fica claro que a perspectiva adotada para se examinar a questão do emprego da pontuação é de natureza processual. Interessa-nos investigar as hipóteses que os aprendizes fazem com relação à utilização dos sinais de pontuação e quais são as funções que esses aprendizes atribuem a esses sinais. Faz-se necessário, portanto, desvelar como se processa a evolução do emprego dos recursos de pontuação quanto a duas distintas questões que se apresentam aos escritores iniciantes:

$1 .^{\mathrm{a}}$ - Por que pontuar e onde pontuar?

$2 .^{a}$ - Ao pontuar, que sinal deverá ser utilizado?

A resposta à primeira questão se insere naquilo que Emilia Ferreiro chamou de aspectos construtivos da escrita. Nela o aprendiz precisa resolver a questão da segmentação do discurso escrito, ou seja, ele precisa definir as partes que deverão ser sinalizadas, organizando, assim, o interior do texto para que seja coerente e coeso, enfim, um texto. ${ }^{2}$

A segunda indagação e sua resposta se inserem não apenas no controle dos aspectos gráficos da pontuação mas, sobretudo, no controle interfigural dos aspectos construtivos pertinentes. A preocupação desloca-se, então, para a indicação da orientação que o leitor deve seguir a fim de recuperar a intenção

1 A partir dos anos 90, verifica-se, no Brasil, uma crescente preocupação na definição do conceito do gênero textual e suas diferentes expressões. A esse respeito, Meurer (2002, p. 28) afirma que “...cada vez mais, evidencia-se a necessidade de novos estudos sobre diferentes gêneros textuais que desenvolvam instrumentais teóricos e práticos para demonstrar que, através de textos orais e escritos, criamos representações que refletem, constróem e/ou desafiam nossos conhecimentos e crenças, e cooperam para o estabelecimento de relações sociais e identitárias". Adotamos a definição de gênero textual expressa por Marchuschi (2002, p. 22-23): "textos materializados que encontramos em nossa vida diária e que apresentam características sócio-comunicativas definidas por conteúdos, propriedades funcionais, estilo e composição característica".

2 Adotamos a nomenclatura sobre os elementos essenciais de um texto propostos por Ingedore Koch, nos livros A coesão textual (1989) e A coerência textual (1990). 
de seu autor, isto é, como devem ser lidas cada uma das partes sinalizadas através de diferentes recursos de pontuação.

Como se vê, o estudo da pontuação na escrita infantil é um assunto complexo e de grande amplitude. Mesmo correndo o risco de um certo reducionismo, propomo-nos um recorte no estudo dos elementos constitutivos da pontuação, concentrando-nos na análise de alguns dos aspectos que envolvem o uso do ponto (.). Parece ser mais razoável inquirir sobre o ponto (.), até porque é ele o primeiro sinal de pontuação a ser maximamente utilizado pelos aprendizes. Isto posto, podemos formular a nossa hipótese geral de trabalho da seguinte maneira:

HG: A gênese da utilização dos sinais de pontuação está correlacionada ao fatiamento discursivo do texto.

Essa hipótese mais geral pode ser desdobrada em duas hipóteses específicas, que formulamos assim:

HE1: No fatiamento discursivo do texto, sinaliza-se, primeiramente, a informação mais importante e depois as menos importantes.

O que a HE1 prevê é que certas informações serão sinalizadas antes que outras. A informação mais importante, que chamaremos aqui de foco, pode corresponder a elementos diferentes, dependendo do tipo textual ${ }^{3}$ considerado. Por exemplo, num texto argumentativo, ela corresponderá à conclusão; num texto narrativo, ela corresponderá ao fato principal daquilo que está sendo narrado, ou seja, àquilo que será retomado na seção de avaliação, se quisermos

3 Entendemos por tipo textual o mesmo que Marcuschi (2002, p. 22): “...uma espécie de seqüência teoricamente definida pela natureza lingüística de sua composição (aspectos lexicais, sintáticos, tempos verbais, relações lógicas)". 
utilizar a terminologia de Labov e Waletzky. Assim, uma vez marcada essa informação mais importante, a isso se seguirá a marcação dos outros tópicos do texto.

Podemos ilustrar essa hipótese com o exemplo abaixo:

Exemplo 1 - texto produzido por um aluno de $1 .^{\mathrm{a}}$ série da rede particular de ensino e que aponta para o emprego do ponto (.) como orientador da intenção discursiva do autor.

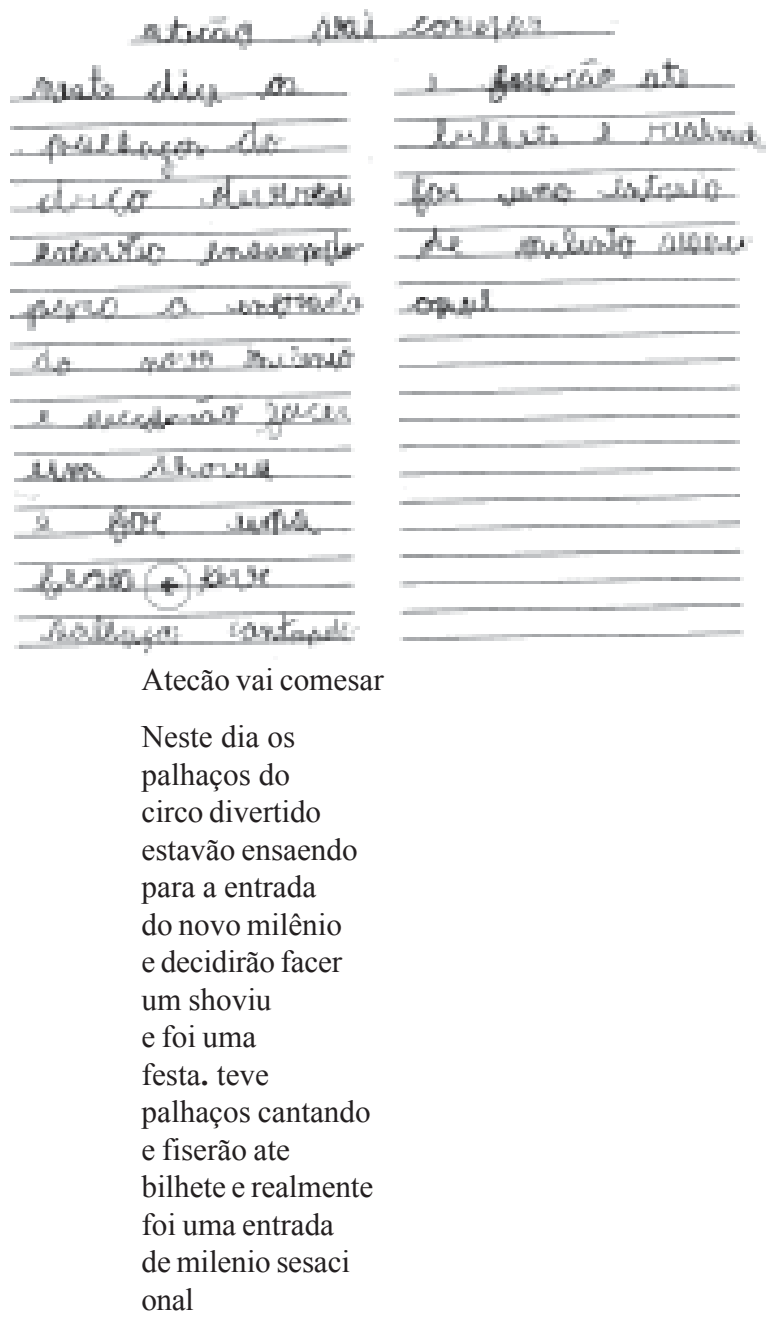


A segunda hipótese específica poderia ser formulada da seguinte maneira:

HE2: O controle interfigural dos sinais de pontuação se esgotará, paulatinamente, através da observação adicional de fatores pontuais (tais como os fatores sintáticos e fonológicos).

Esta hipótese prevê que o ajuste fino da pontuação se dê mais ao final do processo de aprendizado, pela consideração de fatores mais diretamente ligados às partes que compõem o texto, dentro da sua estrutura interna. Aqui entrariam em consideração fatores tais como: a estrutura interna de um sintagma nominal (i.e., se se trata de uma lista, por exemplo), o peso de uma unidade informacional, em termos de sua composição interna (i.e., se a informação é veiculada por um sintagma constituído por muitos ou por poucos elementos), o tipo de ajuste entre orações (tais como coordenação versus subordinação, orações deslocadas ou em ordem direta etc.). Esses fatores certamente repercutirão, commaior ou menor intensidade, na segmentação do texto.

A produção de um aluno da $3 .^{a}$ série da rede pública, representa bem o que acabamos de afirmar:

Exemplo 2 - texto representativo da HE2, no qual a criança demonstra seu esforço em sinalizar as diferentes partes que compõem a estrutura interna do texto, considerando aspectos de natureza sintática, discursiva e fonológica.

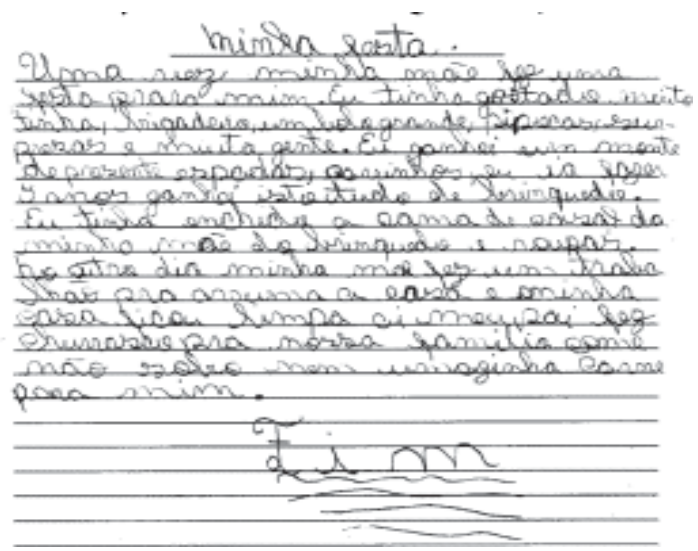


Minha festa.

Uma vez minha mãe fez uma

festa prara mim. Eu tinha gostado muito

tinha,brigadeiro, um bolo grande, pipocas, sur-

presas e muita gente. Eu ganhei um monte

de presente espadas, carrinhos, eu ia fazer

8 anos ganhei isto tudo de brinquedo.

Eu tinha enchido a cama de casal da

minha mãe do brinquedo e roupas.

No outro dia minha mãe fez um traba

lhão pra arruma a casa e minha

casa ficou limpa ai meu pai fez

churrasco pra nossa familia come

não sobro nem umazinha carne

para mim.

Fim

Vale ressaltar que as três hipóteses apontadas sugerem que a pontuação seja regida, na escrita dos aprendizes, por considerações que partem do texto, como um todo, para as suas partes. E é exatamente isso que o quadro teórico utilizado nos leva a supor: o texto, como um todo, é mais saliente do que qualquer uma de suas partes. Fica claro, também, que essas hipóteses sugerem que o caminho que tradicionalmente se percorre em sala de aula, para o ensino da pontuação, se situe, no mínimo, na contramão do aprendiz. O que encontramos, tradicionalmente, é uma tentativa de se lidar com a pontuação através de mecanismos que focalizam o nível da frase, ou através da memorização das regras de ajuste fino da pontuação. Não chega a surpreender, portanto, que o resultado prático disso tudo seja, no geral, uma calamidade.

Registre-se ainda que as hipóteses apresentadas não devem ser vistas como categóricas, mas como sinalizadoras de uma tendência. Não se trata, pois, de uma questão de sim e não, ou de é e não é. Além disso, cabe destacar que as previsões feitas por essas hipóteses não se excluem no eixo do tempo; é sempre possível que um aprendiz desenvolva várias habilidades concomitantemente. Portanto, podemos dizer que as hipóteses apresentadas têm, todas elas, uma natureza probabilística, o que nos obriga a examinar os dados das redações coletadas através de algum tipo de análise quantitativa. 
Feitas essas considerações, podemos nos colocar duas indagações: $o$ que a pontuação representa valorativamente no texto? Essa pergunta é, a rigor, grande demais. Na perspectiva processual adotada aqui, ousamos afirmar que a pontuação indica, principalmente, as intenções e os objetivos discursivos do produtor do texto. Assim sendo, talvez seja mais prudente colocar uma questão menor, a segunda: o que o ponto (.) representa valorativamente no texto?

Essa é a questão que pretendemos responder, ainda que de modo limitado, apresentando os resultados encontrados na análise dos corpora citados. Antes disso, convém informar sobre a metodologia de pesquisa utilizada e o processo de tratamento quantitativo e qualitativo a que foram submetidos os dados das duas pesquisas.

Os dados relativos ao primeiro corpus utilizado foram coletados no segundo semestre de 1987. Os textos deste corpus estão igualmente divididos entre alunos de primeira à quarta série (40 textos de cada série), meninos e meninas (80 textos de cada grupo), de escola pública e escola particular (80 textos de cada grupo) e de alunos de classe social menos favorecida e classe social mais favorecida ( 80 textos de cada grupo). Todo esse material foi coletado durante uma pesquisa sobre o processo de aquisição da escrita, realizada no âmbito da Faculdade de Letras e da Faculdade de Educação da UFMG. Nenhum dos 160 alunos envolvidos era repetente, na série que cursava ou em série anterior. Os textos deste corpus são majoritariamente argumentativos (120 redações), sendo as outras 40 redações divididas entre os tipos narrativo (20 redações) e descritivo (também 20 redações). O desequilíbrio entre os tipos textuais é conseqüência do foco maior que se deu na época às questões de natureza ortográfica. Todos os textos foram coletados em sala de aula, num espaço de tempo de até 40 minutos. O segundo corpus foi coletado por Solange Assumpção, no ano de 1999, como parte de seu trabalho de dissertação de mestrado. Este corpus é constituído por 192 redações, organizadas em 16 blocos de 12 textos, de diferentes tipos textuais ${ }^{4}-3$ narrativos, 5 descritivos, 2 expositivos, 1 injuntivo e 1 argumentativo. Também neste caso, os textos recobrem as séries iniciais do Ensino Fundamental, sendo igualmente distribuídos entre meninos e meninas, entre alunos da rede pública e da rede particular, de alunos de classe social menos favorecida e classe social mais favorecida, e entre as quatro séries. Todos os textos foram coletados em sala de aula, num espaço de tempo de até 90 minutos.

4 Empregamos aqui a classificação de tipos textuais de Marcuschi (2002, p. 22): narração, argumentação, exposição, descrição e injunção. 
A diferença básica entre as duas análises se dá em termos da análise quantitativa escolhida: o primeiro corpus teve seus dados submetidos a testes de significância, em tabulações cruzadas, e a análises de correlação entre variáveis; o segundo corpus foi submetido ao programa $\operatorname{Varbrul}^{5}$ e, para tanto, foi necessário comparar a utilização dos sinais de pontuação, pelas crianças, com a pontuação esperada segundo os padrões gramaticais. Assim, em termos da variável dependente, os casos de desvio da pontuação esperada (quer seja pela sua ausência ou pelo acréscimo de outras marcas gráficas em seu lugar) foram considerados como casos de aplicação de uma regra, enquanto que os casos compatíveis com a pontuação esperada foram classificados como de não aplicação de uma regra. De qualquer forma, nos dois casos procurou-se fazer algum tipo de checagem estatística dos dados no intuito de se comprovar, ou não, as hipóteses levantadas e, portanto, de se fazer as afirmações qualitativas pertinentes com o respaldo de testes. Convém dizer que para todos os testes utilizou-se como nível mínimo de significância o nível 0,05 , ou seja, buscou-se um grau de certeza de pelo menos $95 \%$ para se rejeitar o acaso nas relações encontradas entre as variáveis.

Diversas variáveis foram examinadas nos dois estudos. Mas para se alcançar um grau maior de convergência entre ambos, selecionamos algumas dessas variáveis para o exame da utilização do ponto (.):

1. série: $1 .^{\mathrm{a}}, 2 .^{\mathrm{a}}, 3$. $^{\mathrm{a}} \mathrm{e} 4 .^{\mathrm{a}}$;

2. foco: Se a informação mais importante estava indicada pelo ponto (.), ou não;

3. outros tópicos internos: se outros tópicos internos, que não a informação mais importante, estavam sinalizados pelo ponto (.), ou não;

4. final do texto: Se o final do texto estava indicado pelo ponto (.), ou não;

5. outras marcas: se outros sinais de pontuação, que não o ponto (.), apareciam no texto, ou não;

6. tipo textual: se narrativo, descritivo ou argumentativo;

7. classe social do aluno: se da classe mais favorecida ou da menos favorecida.

5 O pacote de programas Varbrul é uma das opções que os estudiosos da teoria variacionista dispõem para analisar dados lingüísticos de fala. A pesquisa indicada analisa dados de escrita e considera que ocorre variância - um mesmo contexto não assume o mesmo valor de verdade; antes pelo contrário, admite-se a hipótese de que essa marca gráfica seja intencionalmente sinalizada e defina o sentido que se quer dar ao texto - e não variação no emprego do ponto (.). A escolha, então, do pacote Varbrul deveu-se aos recursos de análise disponíveis, prestando-se aos objetivos do referido estudo. 
As variáveis 2 (Foco), 3 (Outros tópicos internos), 4 (Final de texto) e 5 (Outras marcas), que são contempladas pelas hipóteses levantadas anteriormente, podem ser exemplificadas pelos seguintes textos:

Exemplo 3 - texto produzido por uma aluna da 1. ${ }^{\mathrm{a}}$ série da rede pública, sem nenhuma marcação de ponto (.).

\author{
Texto 1 \\ Era uma vez \\ o gatinho Mimi \\ um dia o gatinho \\ viu uma boboleta \\ e o gatinho correl a trás da Boboleta
}

Exemplo 4 - produção de um aluno da 1. ${ }^{\mathrm{a}}$ série da rede particular, na qual o ponto (.) sinaliza apenas a informação principal, ou seja, o foco do texto.

Texto 2

Se eu podesse ecrever mas não tenho papeu.

eu estou com sono espero que mamãe compre

papeu para escrever amanham

Exemplo 5 - texto produzido por um aluno da 2. ${ }^{\text {a }}$ série da rede pública, no qual o ponto (.) indica o término da produção.

\title{
Texto 3
}

se eu podesse brincar no parque eu ia andar na roda jigante no carrinho tombra tombro no topoga eu ina me tiverti muito tambem ia gangora muito.

Exemplo 6 - texto produzido por um aluno da 2. ${ }^{a}$ série da rede pública, sendo a marcação de ponto (.) empregada tanto para indicar a informação principal quanto para sinalizar o final da produção.

\section{Texto 4}

ir ão parque estudar sobre ãs arvores.

todo tipo que puder de arvores estudarei sobre todas e as que não tiverem lá vou noutro tipo de lugar vou estudar tudo que tem de enteressante por lá. 
Exemplo 7 - texto produzido por um aluno da 1. ${ }^{\mathrm{a}}$ série da rede particular, no qual a utilização do ponto (.) marca outros tópicos, que não a informação principal, no interior do texto.

\section{Texto 5}

Eu tenho um brinquedo de montar é o Lego .

Todos os dias eu monto muita coisa .

Ele é o meu brinquedo preferido porque ele é legal.

Quem me deu foi minha tia Samia.

Exemplo 8 - produção de um aluno da 4. ${ }^{\text {a }}$ série da rede pública, na qual pode-se verificar a inserção de outros sinais de pontuação, principalmente a vírgula.

\section{Texto 6}

se eu pudesse fazia coisas maravilhosas . $\leftarrow$ transformava lixos em flores,$\leftarrow$ os riachos sujos eu tirava o sujo aumentava o recreio das crianças,$\leftarrow$ fazia meu pai aposentar para brincar com migo ... $\leftarrow$ fazia os cachorros que tem doença,$\leftarrow$ tirava tudo e dava dinheiro, $\leftarrow$ bastante saúde e felisidade.$\leftarrow$ Dava tudo de bom e abençoado para todos .

Conforme destacado anteriormente, os outros sinais de pontuação que não o ponto (.) serão empregados ao longo do processo de escolarização, sendo que a vírgula constitui cerca de $80 \%$ desses outros sinais. Nas duas séries iniciais, 1. ${ }^{\mathrm{a}}$ e 2. ${ }^{\mathrm{a}}$, o ponto de exclamação (!) vem em segundo lugar, seguido do ponto de interrogação (?), das reticências (...) e dos dois pontos (:). Já nas duas séries finais, $3 .^{\mathrm{a}}$ e $4 .^{\mathrm{a}}$, e principalmente na 4. ${ }^{\mathrm{a}}$, as reticências (...) aumentam sensivelmente sua ocorrência, superando o ponto de exclamação (!).

Como se pode ver, o ponto (.) constitui a primeira opção para se destacar as informações discursivamente escolhidas como relevantes. É basicamente isso o que prevê a nossa hipótese mais geral. Já com relação às duas hipóteses específicas, podemos supor que a análise dos dados vá revelar as seguintes tendências:

a) Não deverá haver nenhuma diferença temporal significante, i.e., entre as séries, seja na marcação da informação mais importante do texto, seja na marcação do texto como um todo (HE1). 
Aqui, dois fatos são esperados. Primeiro, que o texto, enquanto um evento comunicativo, possa ser delimitado em sua totalidade e, segundo, que a informação principal do texto seja igualmente bem delimitada. E se essas são decisões que são tomadas logo de início, não devemos esperar diferenças significativas entre as séries.

b) Poderá haver alguma diferença temporal, i.e., entre as séries, na marcação das informações menos importantes do texto. A segmentação dos tópicos menores tenderá a ser significativamente maior nas séries finais em comparação com as séries iniciais (HE1).

Note-se que a redação dada a esta segunda previsão fica consideravelmente afrouxada, sem nenhuma opção clara. A razão para isso é a seguinte: se o aprendiz não dispõe de conhecimento suficiente para a utilização efetiva de outros sinais de pontuação e, ao mesmo tempo, atribui ao ponto (.) a função de sinalizar apenas a informação principal, é provável que encontremos diferenças significativas entre as séries. Por outro lado, se ao ponto (.) se atribui mais de uma função (por exemplo, a de sinalizar não só a informação principal mas também as outras informações) ou se o aprendiz já dispõe de outras marcas para distinguir as funções, é provável que não encontremos diferenças entre as séries. Trata-se, pois, de uma questão empírica.

c) Deverá haver uma diferença significante no eixo temporal, entre as séries, no ajuste fino da pontuação, ou seja, o ponto (.) deverá ceder lugar a outros sinais de pontuação à medida que se avança na seriação escolar (HE2).

O que se antecipa aqui, é que o aprendiz irá levar em conta fatores ligados aos níveis analíticos que se situam abaixo do nível do texto, ao mesmo tempo em que irá redistribuir a carga funcional atribuída ao ponto (.). Espera-se, portanto, que um melhor desempenho aqui aumente junto com a escalada do aprendiz na seriação escolar.

São essas três suposições que procuraremos testar na análise dos dados, a seguir.

Durante a análise dos dados coletados, várias questões foram levantadas. Em primeiro lugar, indagamos: as redações apresentam uma tendência para sinalizar o foco (ou informação principal) através do ponto (.)? A resposta é sim. Nas 160 redações do primeiro corpus, o foco apareceu seguido de ponto (.) em 124 delas, i.e., em 77,5\% das vezes. No segundo corpus, dois fatos merecem atenção: na intenção de guiar o leitor na construção do sentido do texto, em 
49 afirmativas encontramos o emprego do ponto (.) como limitador visual, ou seja, através do desenho do ponto (.) os aprendizes indicam as informações que desejam salientar e, conseqüentemente, revelam sua intenção discursiva; os grandes blocos de informação, ${ }^{6}$ portanto, de maior carga informacional, apresentaram-se marcados com ponto (.), sendo 201 dos 287 casos de uso do ponto (.) no final de subtópico, $67 \%$ de marcação ao término de quadro tópico e $87 \%$ (157 das 180 ocorrências!) de sinalização nos pontos de encontro entre término de subtópico e quadro tópico. Fica explícita a intenção dos escritores iniciantes em indicar as informações hierarquicamente superiores na estrutura interna do texto. Por sua vez, a marcação de segmento tópico, isto é, a informação fracionada, pertencente a um subtópico, de menor abrangência, é pouco sinalizada: $36 \%$ das ocorrências.

O texto a seguir, produzido por um aluno da $1 .^{a}$ série da rede pública, pode ilustrar o emprego do ponto (.) como revelador da intenção discursiva e da marcação de blocos de maior informatividade:

Exemplo 9 - a criança demarcou a informação "Mas ele chegou a tempo" fazendo uso do ponto (.), um limitador visual, deixando claro para o leitor que, apesar do problema com a condução, tudo terminou bem para o palhaço. Observe-se ainda que o final dos dois subtópicos foi sinalizado, bem como o final do quadro tópico, coincidente com o subtópico "O palhaço chega a tempo".

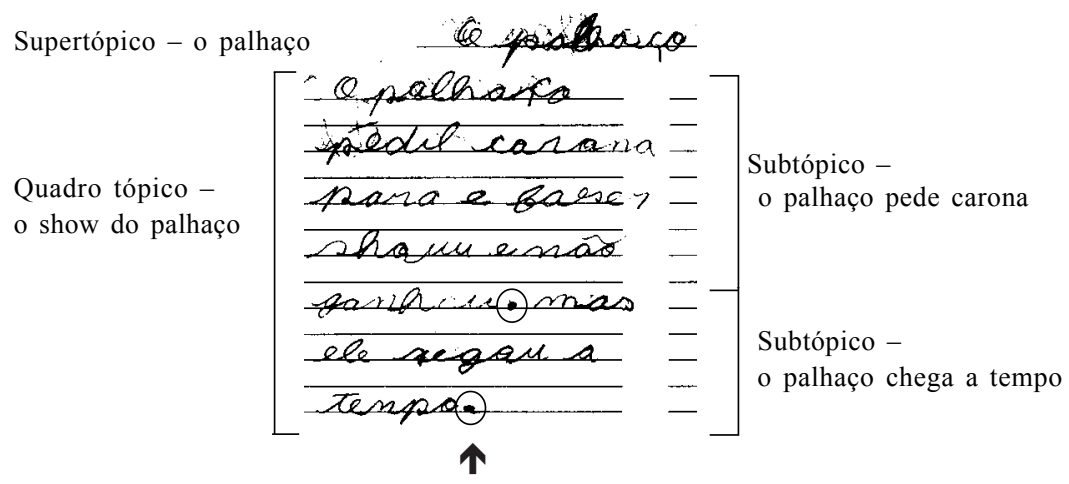

6 Na citada pesquisa, foi empregado o modelo de organização tópica conversacional encontrado em Koch (1997, p. 72). A autora do livro identifica a existência de diferentes níveis de organização tópica, ou seja, é possível encontrar tópicos mais gerais, correspondentes a um fatiamento maior da informação, bem como porções menores de informação. Adotamos aqui a nomenclatura diferenciada para os diversos níveis de fatiamento da informação (do maior para o menor nível de informação): supertópico, quadro tópico, subtópico e segmento tópico. 
A questão que se segue, agora, é: há diferença entre as séries na utilização do ponto (.) como sinalizador do foco? A resposta é não. Neste caso as freqüências de cada uma das séries ficam muito próximas da freqüência geral. Os testes de significância por sua vez, confirmam esse fato.

\begin{tabular}{c|c|c|c|c|c}
\hline Controle por & Qui-2 & $\begin{array}{c}\text { Grau de } \\
\text { liberdade }\end{array}$ & $\begin{array}{c}\text { Rejeitar hipótese } \\
\text { nula? }\end{array}$ & $\begin{array}{c}\text { Coeficiente de } \\
\text { correlação }\end{array}$ & Há correlação? \\
\hline Marca de foco & 0.860 & 3 & Não $(.835)$ & .000 & Não \\
\hline
\end{tabular}

Já no que se refere à utilização do ponto ao final do texto, a freqüência absoluta é quase uma cópia daquela relativa ao foco: encontramos, ao final do texto, uma freqüência geral de $76,9 \%$ de uso do ponto (.). E, novamente, não encontramos diferenças significativas entre as séries.

\begin{tabular}{c|c|c|c|c|c}
\hline Controle por & Qui-2 & $\begin{array}{c}\text { Grau de } \\
\text { liberdade }\end{array}$ & $\begin{array}{c}\text { Rejeitar hipótese } \\
\text { nula? }\end{array}$ & $\begin{array}{c}\text { Coeficiente de } \\
\text { correlação }\end{array}$ & Há correlação? \\
\hline Final de texto & 3.481 & 3 & Não $(.323)$ & .060 & Não \\
\hline
\end{tabular}

Os resultados para a utilização do ponto para marcar o foco e para marcar o final do texto corroboram nossa expectativa inicial de que não haveria diferença significativa entre as séries. Os resultados obtidos decorrem, também, do quadro adotado: o planejamento discursivo se revela na segmentação do texto.

Com relação à marcação dos outros tópicos internos, encontramos um porcentual geral de $73,7 \%$ de marcas através do ponto (.). E, novamente, as diferenças entre as séries não se mostram relevantes.

\begin{tabular}{c|c|c|c|c|c}
\hline Controle por & Qui-2 & $\begin{array}{c}\text { Grau de } \\
\text { liberdade }\end{array}$ & $\begin{array}{c}\text { Rejeitar hipótese } \\
\text { nula? }\end{array}$ & $\begin{array}{c}\text { Coeficiente de } \\
\text { correlação }\end{array}$ & Há correlação? \\
\hline $\begin{array}{c}\text { Marca de tópico } \\
\text { interno }\end{array}$ & 3.228 & 3 & Não $(.354)$ & .127 & Não \\
\hline
\end{tabular}


Contudo, quando juntamos as duas primeiras séries, opondo-as às duas últimas, encontramos um Qui-quadrado de 110.3, o que torna os dois blocos diferentes num nível de certeza de $100 \%$ ! Isto sugere que a incorporação de outras marcas de pontuação e/ou a incorporação de mecanismos sintáticos de ligação entre orações possa estar reduzindo a carga funcional inicialmente atribuída ao ponto (.). Esses fatos se ligam diretamente aos comentários de Assumpção (2001, p. 123) sobre a organização tópica por série, onde na primeira série, das 11 marcas da organização tópica, 9 são feitas pelo ponto (.), num total de $82 \%$ das vezes; já na segunda série, das 29 marcas, 10 são feitas através do ponto (.), num total de $34,5 \%$ das vezes; na terceira série, 1 marca em 23 se dá pelo ponto (.), num total de $4,3 \%$ das vezes e na quarta série, 5 marcas em 27 se dão pelo ponto (.), num total de $18,5 \%$ das vezes. Portanto, podemos dizer que a utilização do ponto (.) para a marcação dos tópicos internos se dá numa relação inversa à incorporação de outras marcas, num ajuste interfigural. E isso nos leva à nossa última questão: o ajuste fino da pontuação se diferencia significativamente no eixo temporal? Nossa previsão é que sim, e a previsão se confirmou. Vejamos os resultados:

\begin{tabular}{c|c|c|c|c|c}
\hline Controle por & Qui-2 & $\begin{array}{c}\text { Grau de } \\
\text { liberdade }\end{array}$ & $\begin{array}{c}\text { Rejeitar hipótese } \\
\text { nula? }\end{array}$ & $\begin{array}{c}\text { Coeficiente de } \\
\text { correlação }\end{array}$ & Há correlação? \\
\hline Outras marcas & 17.845 & 3 & Sim $(.000)$ & $.325 * *$ & Sim (nível sig. 0.01) \\
\hline
\end{tabular}

Esta análise sugere que as três hipóteses apresentadas anteriormente, a geral e as duas específicas, fazem sentido. A pontuação é um processo que se dá do texto para seu interior (e não o contrário!), do discurso para as camadas estruturais que compõem as partes do texto.

Há, ainda, dois aspectos apontados em Assumpção (2001) que gostaríamos de retomar aqui, ainda que brevemente. O primeiro se refere às diferenças relativas aos tipos textuais na pontuação. Conforme Assumpção, nos textos descritivos verifica-se maior incidência de recursos de pontuação do que nos demais. ${ }^{7}$ Realmente, os dados do corpus de 1987 confirmam isso. Mas gostaríamos de relativizar esse fato, até porque ele pode lançar alguma luz sobre

7 A esse respeito, ver Assumpção, op. cit., p. 108-110. 
um ponto ainda não resolvido. É fato que os textos descritivos apresentam, todos eles, o uso do ponto (.) para marcar a informação principal. O mesmo já não acontece com os textos argumentativos e os narrativos.

\begin{tabular}{c|c|c|c|c|c}
\hline Controle por & Qui-2 & $\begin{array}{c}\text { Grau de } \\
\text { liberdade }\end{array}$ & $\begin{array}{c}\text { Rejeitar hipótese } \\
\text { nula? }\end{array}$ & $\begin{array}{c}\text { Coeficiente de } \\
\text { correlação }\end{array}$ & Há correlação? \\
\hline Marca de foco & 6.882 & 2 & Sim (.032) & $.161{ }^{*}$ & Sim (nível sig. 0.05) \\
\hline
\end{tabular}

Se considerarmos as outras variáveis, vemos que não há diferenças significativas entre os vários tipos textuais.

\begin{tabular}{c|c|c|c|c|c}
\hline Controle por & Qui-2 & $\begin{array}{c}\text { Grau de } \\
\text { liberdade }\end{array}$ & $\begin{array}{c}\text { Rejeitar hipótese } \\
\text { nula? }\end{array}$ & $\begin{array}{c}\text { Coeficiente de } \\
\text { correlação }\end{array}$ & Há correlação? \\
\hline Final de texto & 2.543 & 2 & Não $(.280)$ & .083 & Não \\
\hline $\begin{array}{c}\text { Marca de tópico } \\
\text { interno }\end{array}$ & 5.725 & 2 & Não $(.057)$ & .138 & Não \\
\hline Outras marcas & 0.100 & 2 & Não $(.951)$ & .009 & Não \\
\hline
\end{tabular}

Vale destacar que os números sugerem que a marcação da informação principal (ou foco, na perspectiva aqui adotada) seja um critério mais forte do que a marcação do texto como um todo, i.e., a marcação ao final do texto. Contudo, consideramos que esta ainda seja uma questão em aberto.

$\mathrm{O}$ segundo aspecto se refere às diferenças de classe encontradas, fato também já apontado em Assumpção (2001, p. 130) e replicado no corpus de 1987.

\begin{tabular}{c|c|c|c|c|c}
\hline Controle por & Qui-2 & $\begin{array}{c}\text { Grau de } \\
\text { liberdade }\end{array}$ & $\begin{array}{c}\text { Rejeitar hipótese } \\
\text { nula? }\end{array}$ & $\begin{array}{c}\text { Coeficiente de } \\
\text { correlação }\end{array}$ & Há correlação? \\
\hline Marca de foco & 17.348 & 1 & $\operatorname{Sim}(.000)$ & $.329^{* *}$ & Sim (nível sig. 0.01) \\
\hline Final de texto & 18.598 & 1 & $\operatorname{Sim}(.000)$ & $.341^{* *}$ & Sim (nível sig. 0.01) \\
\hline $\begin{array}{c}\text { Marca de tópico } \\
\text { interno }\end{array}$ & 25.311 & 1 & $\operatorname{Sim}(.000)$ & $.398^{* *}$ & Sim (nível sig. 0.01) \\
\hline Outras marcas & 36.190 & 1 & $\operatorname{Sim}(.000)$ & $.476^{* *}$ & Sim (nível sig. 0.01) \\
\hline
\end{tabular}


Segundo Assumpção (2001, p. 130), o melhor desempenho das classes mais favorecidas se explicaria "pelo contato sistemático que têm com as práticas sociais de leitura e escrita". Parece-nos que o caminho é esse mesmo, mas é bom que se leve em conta a prática de sala de aula: o que observamos, no corpus de 1987, foi que os alunos que se alfabetizavam por métodos que iam do texto para as suas partes (o global, por exemplo) se saiam melhor, na produção textual, do que os alunos que se alfabetizavam por métodos que iam das partes do texto para o texto como um todo (o fônico, por exemplo), independentemente de sua condição social. Como esse aspecto não foi examinado em detalhe, vamos deixálo como objetivo para um trabalho futuro.

\section{Conclusão}

Para concluir a apresentação, gostaríamos de voltar a Schneuwly (1988). O autor divide em quatro tipos as operações encontradas na escrita das crianças: segmentação, conexão, coesão e modalização. Em seu trabalho, Schneuwly exemplifica as operações de segmentação através de uma análise da pontuação. As relações de conexão são operacionalizadas pelos chamados organizadores $\mathrm{e}$, neste caso, Schneuwly as ilustra com a conjunção $e$ enquanto organizador temporal e não-temporal. Nessa obra, Schneuwly apresenta o duplo caráter da pontuação: ao mesmo tempo em que a pontuação segmenta o texto, ela o organiza. A pontuação delimita no texto as suas unidades e, ao mesmo tempo, as organiza e as conecta. O que a análise dos dados apresentada aqui sugere é que a utilização da pontuação, principalmente do ponto (.), para se fatiar as unidades textuais, é algo que se dá bem no início do processo de aquisição da escrita. Por outro lado, a organização adequada do texto, no que se refere à pontuação, é um processo que se dá ao longo do tempo. Este é um processo que, ao mesmo tempo em que incorpora novos sinais de pontuação e outras estratégias, realoca funções anteriormente atribuídas ao ponto (.). Por fim, o presente artigo corrobora com as pesquisas mais recentes sobre o processo de apropriação da língua escrita por escritores iniciantes: os aprendizes têm um papel ativo nesse processo, levantam hipóteses sobre o papel da pontuação no texto escrito e se orientam por meio de uma lógica - na maioria das vezes, divergente do adulto - que baliza suas escolhas reais, manifestas no espaço sociocultural chamado texto. 


\section{RESUMO}

O ponto (.) tem sido tratado, tradicionalmente, como um recurso para indicar uma pausa máxima de voz que ocorre após um grupo fônico de final descendente. Nesta mesma perspectiva, se trabalha o ponto (.) nas séries iniciais do Ensino Fundamental. Nos casos em que os autores consagrados se utilizam do ponto (.) onde tradicionalmente se esperaria um ponto e vírgula, ou uma vírgula, costuma-se dizer que estamos diante de um "eficiente recurso estilístico" (cf. Cunha, 1970). Mas como é que os aprendizes se utilizam do ponto (.) em suas produções escritas nas séries iniciais? O objetivo deste texto é mostrar, a partir da análise da produção escrita de alunos das quatro primeiras séries do Ensino Fundamental, quais são as funções atribuídas por estes mesmos alunos ao ponto (.). Nosso quadro de análise pode ser caracterizado como sendo o do interacionismo sociodiscursivo de Bronckart (1999) e das propostas de Beaugrande (1997) para uma ciência do texto e do discurso. Para examinar as redações que constituíram o nosso corpus, valemo-nos de uma análise estatística em que procuramos controlar tanto a utilização quanto a não utilização do ponto (.). Portanto, consideramos a presença do ponto (.) nas situações previstas e não previstas pelas regras de pontuação, assim como a ausência do ponto (.) onde, de acordo com essas mesmas regras, ele deveria ter ocorrido. Nossa análise dos dados indicou que o emprego do ponto (.) mantém estreita relação com a organização tópica do texto. Os alunos privilegiam os tópicos de maior extensão, as porções de informação mais bem delimitadas e as unidades de informação que tenham sido, discursivamente, colocadas em foco.

Palavras-Chave: língua portuguesa, aquisição da escrita, pontuação.

\section{ABSTRACT}

The full stop has been traditionally considered as a device to indicate a maximum vocal pause that occurs after a final downward phonic cluster. It is in this perspective that it is taught in elementary school. In those cases in which famous authors use the full stop instead of the expected comma or semi-colon, prescriptive grammarians say that we are witnessing "an efficient stylistic strategy" (cf. Cunha, 1970). But the question is: how do learners of the written language use the full stop in their first written productions? The aim of this paper is to shed light, on the basis of an examination of first to fourth grade student texts, on the functions these students assign to the full stop. The analytical framework we use here is the sociodiscoursive interactionism of Bronckart (1999) and de Beaugrande's conceptions about the text. The data of the corpus were submitted to a statistical analysis in which both the presence and the absence of the full stop were taken into account. The results of this quantitative analysis have indicated that the use of the 
OLIVEIRA, M. A.; ASSUMPÇÃO, S. R. B. Para além da frase:...

full stop is strongly correlated with the topic organization of the text. The students use the full stop to signal longer topics, information units that are better designed as well as information units, which have been elected as the focus of the discourse.

Key-words: Early child language acquisition, the functional character of punctuation, punctuation and flow of information.

\section{REFERÊNCIAS}

ASSUMPÇÃO, Solange R. Bonomo. O jogo da pontuação: a construção do sentido na tessitura da escrita. Belo Horizonte, 2001. Dissertação (Mestrado) - Universidade Federal de Minas Gerais.

BEAUGRANDE, Robert de. New foundations for a science of text and discourse: cognition, communication and freedom of access to knowledge and society. Norwood: Ablex Publishing Corporation, 1997.

BRONCKART, Jean-Paul. Atividade de linguagem, textos e discurso: por um interacionismo sociodiscursivo. São Paulo: Educ, 1999.

CUNHA, Celso. Gramática do português contemporâneo. Belo Horizonte: B. Alvarez S. A., 1970.

KOCH, Ingedore G. Villaça. A coesão textual. São Paulo: Contexto, 1989.

. A coerência textual. São Paulo: Contexto, 1990.

. A inter-ação pela linguagem. 3. ed. São Paulo: Contexto, 1997.

LABOV, William; WALETZKY, Joshua. Narrative analysis. In: HELM, June (Ed.). Essays on the verbal and visual arts. Seattle: University of Washington Press, 1967, p. 12-44.

MARCUSCHI, Luiz Antônio. Gêneros textuais: definição e funcionalidade. In: DIONÍSIO, Ângela Paiva et al. (Orgs.). Gêneros textuais \& ensino. Rio de Janeiro: Lucerna, 2002. p. 19-36.

MEURER, José Luiz; MOTTA-ROTH, Désirée (Orgs.). Gêneros textuais e práticas discursivas: subsídios para o ensino da linguagem. Bauru: Edusc, 2002. p. 17-29.

SCHNEUWLY, Bernard. Le langage écrit chez l'enfant. Neuchâtel: Delachaux \& Niestlé, 1988. 